\section{The solitaire illusion: An illusion of numerosity}

\author{
CHRISTOPHER D. FRITH \\ Institute of Psychiatry, London University, London, England \\ and \\ UTA FRITH \\ MRC Developmental Psychology Unit, London, England
}

A new illusion in which the apparent number of elements of two kinds is determined by their spatial arrangement is described. The illusion is such that one large cluster appears to contain more elements than several small clusters, clustering being determined by Gestalt principles. The illusion was found both in adults and in children of 8 years.

The illusion illustrated in Fig. 1 was first observed by the authors on a solitaire marble board. With marbles of one color in the positions marked • and marbles of another color on positions marked by $\circ$, there always appeared to be more marbles in the position marked by $\bullet$, whatever their color. The reason for this compelling illusion must therefore lie in the arrangements of its elements. A possible hypothesis is that the elements in the position, by reason of contiguity, form a single unit, or Gestalt, whereas the $\circ$ elements are separated by distance and the elements to form many small clusters. A single big cluster might appear to contain more elements than many small clusters. Piaget $(1966,1968)$ states that in young children there is a tendency to estimate quantity or number in terms of space occupied. It may be that adults, too, sometimes base numerosity estimates on spatial perceptual factors and thus are subject to illusions, as in the case in point. In order to test the hypothesis that a big cluster suggests greater quantity than many small clusters, which do not form a Gestalt, a series of figures was constructed which could potentially induce illusions of number. The degree of illusion was tested in both adults and children.

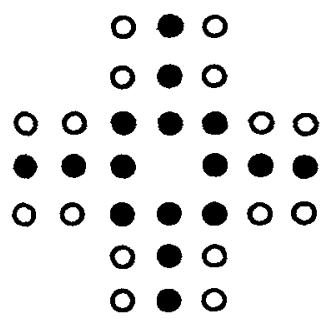

Fig. 1. The solitaire illusion: Positions marked by - appear to be more numerous, although there are as many $\bullet s$ as there are os.
A

D

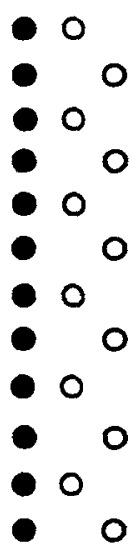

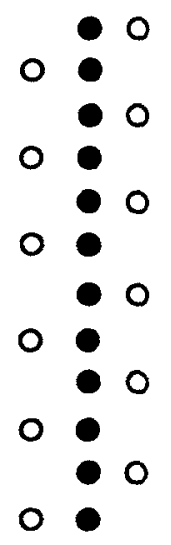
separation.
12 elements of one color $(\bullet)$. The arrangement of the remaining 12 elements of a second color (o) was varied systematically according to two factors. Either all 12 were on one side of the row of $\bullet s(D, E, F)$ or 6 were on one side and 6 on the other $(A, B, C)$. The spatial separation of the 12 os from each other was such as to give clusters containing 1,3 , or 6 elements.

\section{SUBJECTS AND PROCEDURE}

The material was presented to 18 8-year-olds and to 13 adult postgraduate students. Each figure was presented very briefly (for $1 \mathrm{sec}$ ), and the $S$ was asked to estimate whether there were more elements of one color or of the other. The order was randomized. In addition, after the series, the original solitaire illusion was shown.

\section{RESULTS}

Scores were based on frequencies of how often - or $\circ$ elements were thought to be more numerous
B

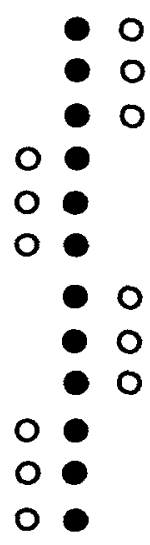

E

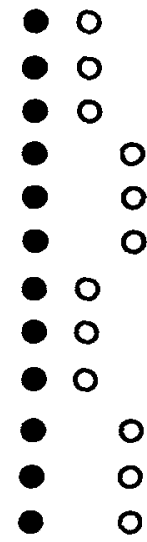

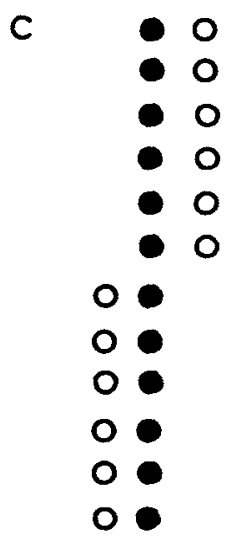

$F$

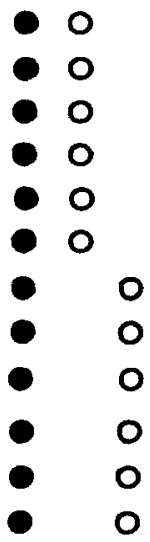

Fig. 2. Experimental material: Positions marked by - were predicted to be judged more numerous. The six figures show varying degrees of clustering and 
Table 1

Number of Children and Adults Showing the Predicted Illusion in the $V$ arious Experimental Conditions

N Cluster Size

\begin{tabular}{lcrrr} 
& Divided Clusters & \multicolumn{1}{c}{ (A, B, C) } \\
Children & 18 & 3 & 6 & 1 \\
& & 18 & 15 & 13 \\
Adults & 13 & 3 & 6 & 1 \\
& & 12 & 13 & 13
\end{tabular}

Undivided Clusters (D, E, F)

\begin{tabular}{lrrrr} 
Children & 18 & 3 & 6 & 1 \\
& & 14 & 12 & 8 \\
Adults & 13 & 3 & 6 & 1 \\
& & 7 & 5 & 4 \\
\hline
\end{tabular}

(Table 1). A clear-cut illusion was found in the predicted direction for both adults and children when the 12 - elements were separated on each side of the elements (A, B, C). Each figure showed a significant effect on a sign test at levels of $p<.01$ or $<.001$. This effect was so strong that no effect of the spatial arrangement of the 0 elements in small clusters of varying size could be observed in this condition.

When the $\circ$ elements were not separated by the - elements (D, E, F), the illusion was very weak both in adults and children. Indeed, for the figure with "clusters" of 1 , the illusion was reversed. Clearly, in this figure (D), there are not 12 clusters of 1 , but 1 cluster of 12, and these $12 \circ$ elements occupied a greater space than the 12 elements and hence fall at the opposite end of the series of illusions to that anticipated. Thus, in this condition, clusters of $3(E)$ produced a weak predicted illusion, clusters of 6 (F) showed no illusory effect, and "clusters" of 1, i.e., 12, showed a weak reversed illusion. Taking adults and children together, there was a significant difference between the effect of clusters of Sizes 3 and 12 $\left(x^{2}=4.15, p<.05\right)$.

There was no effect due to vertical or horizontal presentation of the material. The solitaire illusion was strong in both children (13 out of 18 ) and adults (12 out of 13 ).

\section{DISCUSSION}

The origin of the solitaire illusion seems to lie in a relative underestimation of the number of elements if they are distributed in several small higher-order units or clusters, as opposed to one single higher-order unit. A higher-order unit in this context is the same as a "Gestalt," and its existence in the present experiment has been determined by the principles of contiguity and spatial separation (Wertheimer, 1923). The strongest effect contrasting grouping into one unit and groupings into smaller units was achieved by placing the elements of one color between elements of the other color. Spatial separation alone produced a much smaller, though significant, effect.

The lack of differentiation between the age groups indicates that the mechanism responsible for the illusion is present at least by the age of 8 . Pick and Pick (1970), discussing developmental studies of perceptual illusions, point out that a direct relationship between susceptibility $+J$ an illusion and intelligence or age is not always found. This is in conflict with the classical empiricist position which emphasizes the effects of experience on perception. The solitaire illusion does not appear to decrease with frequent and long inspection. This, and the lack of change with age, may suggest that the effect is determined by basic perceptual factors which are probably not linked to intelligence or experience.

\section{REFERENCES}

PIAGET, J. Quantification, conservation and nativism. Science, 1968, 162 976-979.

PIAGET, J. \& INHELDER, B Mental imagery in the child, London: Routledge 8 Kegan Paul, 1971 (First published in 1966).

PICK, H. L., JR., 8 PICK, A, D. Sensory and perceptual development. In P. H. Musgen (Ed.), Carmichael's manual of child psychology. Vol. 1. Chapter II. New York: Wiley, 1970. Pp. 773-847.

WERTHEIMER, M. Untersuchungen zur Lehre von der Gestalt. Psychologische Forschung, 1923, 4, 301-350.

(Accepted for publication January 13 , 1972.) 